\title{
Control of Bone Homeostasis by the Wnt Inhibitor Sclerostin
}

\author{
Meghan E. McGee-Lawrence $^{1}$ - Mark W. Hamrick ${ }^{1}$
}

Published online: 23 June 2016

(C) Springer International Publishing AG 2016

\begin{abstract}
Wnt signaling is an important osteogenic pathway regulating skeletal development and maintenance, and sclerostin is a potent extracellular inhibitor of this process. New anabolic skeletal therapies are needed to treat osteoporosis in the aging population, and pre-clinical and clinical studies demonstrate that targeting sclerostin with neutralizing antibodies releases an inhibitory brake on osteogenic Wnt signaling, promoting new bone formation and suppressing bone resorption to ultimately increase net bone mass. In this article, we review recent evidence regarding the regulation of sclerostin production in vivo under normal and disease states and summarize recent findings regarding the efficacy, mechanism of action, and potential complications of sclerostintargeting therapies (i.e., sclerostin-neutralizing antibodies) in the treatment of skeletal disorders. While recent studies have revealed a great deal of information regarding sclerostin's biological effects and regulatory patterns, much remains to be learned about the role of this molecule in the skeleton and other body systems.
\end{abstract}

Keywords Sost · Wnt · Romosozumab · Osteogenesis · Osteoporosis $\cdot$ Bone formation

This article is part of the Topical Collection on Stem/Progenitor Cells Biology and Regeneration

Meghan E. McGee-Lawrence

mmcgeelawrence@augusta.edu

1 Department of Cellular Biology \& Anatomy, Medical College of Georgia, Augusta University, Augusta, GA 30912, USA

\section{Introduction}

Osteoporosis is the most common bone disease in humans; 54 million Americans either presented with or were at risk for this disorder in 2010 [1, 2], and these numbers will grow exponentially with the aging American population [3]. The most widely used osteoporosis treatments (e.g., anti-resorptive bisphosphonates or RANKL-inhibiting denosumab) slow bone loss, but they do not build new bone or counteract ageinduced loss of osteoblastic differentiation potential from progenitor cells [4]. Parathyroid hormone (PTH) therapy, in the form of teriparatide, is the only FDA-approved agent that stimulates new bone formation, and its clinical usage is limited to an 18-month "anabolic window" of efficacy [5].

Wnt signaling has long been recognized as an important osteogenic pathway in the regulation of skeletal development and regeneration. In canonical Wnt signaling, binding of Wnt ligands to Frizzled and Lrp5/6 co-receptors stabilizes $\beta$-catenin, allowing it to accumulate in the cytosol, translocate to the nucleus, and upregulate expression of Wnt target genes, resulting in stimulation of osteoblast progenitor proliferation and differentiation. Sclerostin, encoded by the SOST gene, is an extracellular inhibitor of the canonical Wnt pathway. This predominant osteocyte-produced glycoprotein was identified through genetic screening of patients with the sclerosing bone disorders sclerosteosis and van Buchem's disease, locating genetic mutations in the SOST gene or its regulatory elements that produced a high bone mass phenotype in affected patients [6-8]. Sclerostin antagonizes Wnt signaling by binding to Lrp4, 5, and 6 co-receptors $[9,10]$, blocking the ability of Wnt ligands to bind and stimulate downstream signaling. Although primarily produced by osteocytes, sclerostin expression has also been detected in other cells like aged osteoclasts [11], calcifying vascular tissue [12, 13], and synoviocytes [14••]. As an inhibitor of Wnt signaling, sclerostin suppresses 
both osteoblastic differentiation and activity $[15,16]$. Additionally, sclerostin stimulates RANKL expression in osteocytes, promoting osteoclastic bone resorption [17]. Accordingly, sclerostin-deficient mice develop high bone mass resulting from an immense increase in osteoblastic bone formation and smaller but significant decreases in osteoclastic bone resorption $[18,19]$.

In this article, we review recent evidence regarding the regulation of sclerostin production in vivo under normal and disease states and summarize recent findings regarding the efficacy of sclerostin-targeting therapies (i.e., sclerostinneutralizing antibodies) in the treatment of skeletal disorders.

\section{Regulation of Sclerostin Production}

As a powerful inhibitor of osteoblastic bone formation, sclerostin levels must be tightly regulated in the body. Recent findings regarding physiological regulators of Sost and sclerostin expression are summarized below. Although excellent earlier literature exists on many of these topics, we have made an effort to highlight the results of recent studies (published within the past five years).

\section{Parathyroid Hormone}

It has been known for over a decade that PTH treatment suppresses sclerostin production by human and murine osteocytes $[16,20,21]$. Several recent reports have confirmed this phenomenon in vivo, demonstrating that serum sclerostin levels are negatively correlated with PTH levels in non-diabetic patients [22] and decline in response to an acute infusion of PTH [23]. Additionally, Sost overexpression abrogates increases in cortical and cancellous bone mass caused by constitutively active PTH1R signaling [24]. Suppression of sclerostin by PTH requires the presence of the Wnt receptor LRP6 [25] and occurs, at least in part, through the nuclear accumulation of histone deacetylase 5 (Hdac5). Hdac5, in turn, subsequently inhibits myocyte enhancer factor 2 (MEF2)-dependent stimulation of the Sost bone enhancer [26•,27] (discussed in detail below).

\section{Sex Steroids (Estrogen, Testosterone)}

In general, the sex steroids appear to inhibit sclerostin production, best evidenced by the fact that sclerostin levels increase in the case of sex steroid deficiency $[28,29]$. Estrogen treatment of postmenopausal women decreases circulating sclerostin $[28,29]$, but the role of testosterone is more controversial. One study demonstrated that treatment with estrogen, but not testosterone, prevents increases in sclerostin levels following induction of acute sex steroid deficiency [28]. However, serum sclerostin levels are negatively correlated with testosterone in male human patients, and treatment of human osteocytes with dihydrotestosterone (DHT) reduces Sost expression in these cells, suggesting a potentially important role for testosterone in the biology of sclerostin regulation [20].

\section{Vitamin D}

The Sost gene is positively regulated by $1 \alpha, 25$ dihydroxyvitamin $\mathrm{D}(1,25 \mathrm{D})$, as both Sost messenger RNA (mRNA) and sclerostin protein are rapidly increased in response to $1,25 \mathrm{D}$ treatment in osteocyte-differentiated human $\mathrm{SaOS} 2$ cells $[30,31]$. While sclerostin expression is not necessarily altered by vitamin D deficiency in adults, sclerostin levels are suppressed in babies born to vitamin $\mathrm{D}$ deficient as compared to vitamin $\mathrm{D}$ sufficient mothers [32]. However, the role of vitamin $\mathrm{D}$ in Sost regulation is not completely clear, as conflicting evidence exists. For example, murine Sost gene expression is suppressed by $1,25 \mathrm{D}$ treatment in IDG-SW3 cells near the end of the osteoblast-to-osteocyte transition period (i.e., near the time when the cells are considered mature osteocytes) [33]. Interestingly, Sostdeficient mice demonstrate increased serum levels of $1,25 \mathrm{D}$, resulting, in part, from enhanced expression of 25-hydroxyvitamin D $1 \alpha$-hydroxylase cytochrome P450 (cyp27B1) in the kidney [18]; this could represent a compensatory mechanism driven by the absence of circulating sclerostin in the knockout animals but more likely reflects the drive for a positive mineral balance to support increased bone formation in the sclerostindeficient animals.

\section{Mechanical Loading}

Bone is a mechanoresponsive tissue, demonstrating hypertrophy in response to increased mechanical loading and atrophy in response to disuse. Mechanical loading suppresses sclerostin production both in vitro (e.g., fluid flow loading of osteocytes) [34] and in vivo (e.g., ulnar axial loading) [35]), whereas disuse increases sclerostin expression in vitro [36•] and in vivo [37]. Loading-induced sclerostin suppression requires production of nitric oxide, as inhibition of nitric oxide synthase prevents the fluid flow-induced suppression of Sost expression [38]. Administration of sclerostin-neutralizing antibodies abrogates bone loss caused by disuse from hindlimb suspension [39], spinal cord injury [40•], and limb immobilization [41], even when disuse is superimposed over a concurrent effect of estrogen depletion from ovariectomy [42]. 


\section{Epigenetic Mechanisms}

Surprisingly, both circulating and bone mRNA expression of Sost are lower in osteoporotic as compared to healthy women [43], despite the fact that sclerostin suppresses bone formation. Subsequent analysis of this phenomenon revealed that the Sost promoter is more methylated in patients with established osteoporosis as compared to healthy controls, suggesting that methylation to reduce Sost gene expression could be a protective mechanism triggered to help reduce inhibition of Wnt signaling and promote bone formation in osteoporotic patients [43].

Beyond methylation, other epigenetic mechanisms may also influence Sost production. Knockdown of Hdac5 increases Sost expression, and overexpression of Hdac 5 suppresses Sost expression in osteocytes, and Hdac5-deficient mice show increased expression of Sost and lower Wnt activity. This effect occurs through modulation of the Mef2c transcription factor. Sost expression is increased via binding of the transcription factor Mef2c to a distal enhancer region (ECR5) [44], and Mef2C binding at this location is enhanced in the case of Hdac5 deficiency [26•].

\section{Sclerostin Levels in Human Disease}

Many diseases are intertwined with skeletal biology, causing loss of bone mass secondary to organ dysfunction elsewhere in the body. Recently, it has emerged that some of these skeletal phenotypes may be linked with altered circulating levels of sclerostin, as discussed below.

\section{Diabetes}

Diabetes mellitus is associated with increased risk of bone fracture $[45,46]$, and patients may present with reduced bone turnover, suggesting a potential regulatory role for sclerostin in this phenotype [22]. Recent reports indicate that circulating sclerostin levels are increased in both type 1 and type 2 diabetic patients as compared to healthy controls [22, 47], although levels are not different between type 1 and type 2 diabetic patients [48]. This increase likely begins in the prediabetic phase when insulin resistance develops, as sclerostin levels are increased in patients with impaired glucose regulation (prior to onset of overt diabetes) as compared to normoglycemic controls and are positively correlated with homeostatic model assessment of insulin resistance (HOMA-IR) [49••]. In patients with type 2 diabetes, sclerostin levels are elevated in patients presenting with fragility fractures compared with non-fractured diabetic controls [50], and higher sclerostin levels are associated with an increased risk of vertebral fractures independent of BMD [51], supporting a role for sclerostin in the fracture-prone phenotype of diabetic patients.
In contrast to this finding, one study revealed that type 1 diabetes patients with the highest tertile of circulating sclerostin levels had decreased risk of fracture; the biological explanation for this confounding observation is not yet known [52].

\section{Kidney Disease}

Renal osteodystrophy is a common complication of chronic kidney disease, and the most common type of osteodystrophy in end-stage renal disease is one with low turnover [53]. Sclerostin levels are increased in patients with chronic kidney disease (CKD) both pre- and post-dialysis [12, 54, 55] as compared to healthy controls, with the highest expression occurring at early stages of the disease [56]. At least one study suggests that these high levels of sclerostin are inversely correlated with bone formation rates, potentially contributing to renal osteodystrophy in this patient population [57]. High circulating sclerostin levels in patients with kidney disease are rescued by renal transplantation [58]. Interestingly, circulating sclerostin levels are increased in dialysis patients that develop vascular calcifications as compared to dialysis patients free from calcification complications [12]. Although sclerostin is predominantly produced by osteocytes in vivo, its expression is detected by immunohistochemistry and real-time PCR in aortic valves developing calcification as compared to noncalcified valves [12], suggesting that sclerostin could play a role in the biomineralization of extraskeletal tissues.

\section{Liver Disease}

Serum sclerostin levels appear to increase the case of liver dysfunction. Several recent reports indicate that sclerostin levels are elevated in patients with cirrhosis as compared to healthy controls [59-61]. The mechanism for the increased sclerostin in cirrhotic patients is not yet known, but proposed contributing factors have included increased retention secondary to liver dysfunction and altered expression of sex steroids [59].

\section{Human Immunodeficiency Virus}

Patients infected with human immunodeficiency virus (HIV) often develop low bone mass and subsequent fragility fractures [62]. It was recently reported that sclerostin levels are suppressed in HIV infected as compared to healthy controls for a small cohort of adult patients (33 HIV, 63 controls) [63]. These findings are supported by a second study suggesting reduced sclerostin levels in HIV-infected youths and adolescents as compared to healthy controls [64]. As sclerostin levels were not correlated with bone mineral density in this population, these results raise the possibility that immune function or systemic inflammation could regulate serum sclerostin in HIV-affected patients [63]. 


\section{Sclerostin Inhibition as an Anabolic Skeletal Therapy}

Given the paucity of FDA-approved anabolic skeletal therapies presently on the market, inhibition of sclerostin activity is an attractive target for new osteogenic drug development. The application of sclerostin-neutralizing antibodies (Scl-Abs) for increasing bone mass has been under investigation at least since 2009, when short-term administration of Scl-Ab therapy was shown to improve bone formation, mass, and strength in an ovariectomized rat model of osteoporosis [65]. Below, we summarize recent findings from animal and human studies continuing to pursue this goal and discuss some potential complications that could arise from use of Scl-Ab treatments.

\section{Osteoporosis}

Many recent animal studies have focused on better understanding Scl-Ab's mechanism of action, revealing novel effects on bone formation and bone resorption. Whereas bisphosphonate therapies primarily decrease bone resorption and teriparatide administration stimulates increased bone remodeling, Scl-Ab treatments increase bone mass by promoting modeling-based bone formation and simultaneously reducing bone resorption while extending the bone formation period at modeling and remodeling sites [66]. In cortical bone, Scl-Ab promotes both periosteal and endocortical bone formations, leading to a net increase in bone mass [67, 68]. Although Scl-Ab's ability to stimulate bone formation in vivo is limited to the early phases of treatment, its ability to suppress bone resorption is sustained for a much greater length of time $[67,69,70]$. Osteoblasts, bone lining cells, and osteocytes collected by laser capture microdissection from Scl-Ab-treated ovariectomized rats show upregulated expression of canonical Wnt targets and genes related to matrix synthesis and mineralization, as would be expected, but surprisingly show no alteration in expression of genes related to osteoclastogenesis (e.g., RANKL) [71], even though sclerostin itself promotes RANKL expression in osteocytes [17].

In humans, two $\mathrm{Scl}-\mathrm{Ab}$ therapies are at various stages of clinical development as treatments for post-menopausal osteoporosis: romosozumab, developed by Amgen/UCB, and blosozumab, developed by Eli Lilly. Results from phase II trials of romosozumab were published in 2014, demonstrating that all tested dose levels of romosozumab increase bone mineral density at the lumbar spine, total hip, and femoral neck as compared against placebo treatment $[72 \bullet \cdot]$. Moreover, high doses of romosozumab (210 mg, delivered monthly) increase bone mineral density at each of these sites to a greater degree than treatment with the anti-resorptive bisphosphonate alendronate or the anabolic agent teriparatide $[72 \bullet \bullet]$. Preliminary results from a much larger phase III trial of romosozumab were presented in April of 2016, demonstrating that 12 months of treatment with romosozumab increases bone mineral density at the total hip and lumbar spine and estimated bone strength at the hip by a greater amount than teriparatide in osteoporotic postmenopausal women [73]. With regard to fracture prevention, recent reports summarizing phase III results indicate that romosozumab reduces the incidence of new vertebral fractures and clinical fractures in postmenopausal women with osteoporosis.

Phase II trials of blosozumab were published in 2015, demonstrating that 12 months of treatment with blosozumab dosedependently increases bone mineral density at the lumbar spine, femoral neck, and total hip as compared with placebo treatment [74•]. Bone mass gained with blosozumab treatment appears to be maintained, as bone mineral density at the lumbar spine and total hip remains greater in blosozumab treated as compared to placebo-treated postmenopausal women [75•].

Regarding other forms of osteoporosis, clinical trials to investigate the efficacy of romosozumab to combat agerelated osteoporosis in men are ongoing $[76 \bullet, 77 \bullet \bullet]$ but have not yet been reported for blosozumab. Notably, circulating sclerostin levels increase with age in humans, although bone mRNA levels of SOST are not increased with age, suggesting that extraskeletal production of sclerostin may contribute to these aging-related changes [78]. Scl-Ab therapies have also proved efficacious for abrogating bone loss in other osteoporosis models including glucocorticoid- and disuse-induced osteoporosis. For example, administration of Scl-Ab therapy prevents prednisolone-induced bone loss in mice [79] and blocks disuse-induced bone loss after spinal cord injury in animal models $[40 \cdot$, 80].

\section{Osteogenesis Imperfecta}

Osteogenesis imperfecta (OI) is a genetic disorder caused by mutation in type 1 collagen, the major organic component of bone, resulting in a fragile skeleton. Anti-resorptive bisphosphonates have shown some efficacy at preventing fractures in this patient population [81, 82], but Scl-Ab therapies are being considered as new therapeutic approaches to increase bone mass and prevent fractures in OI patients. Although sclerostin antibody treatment cannot rescue the genetic defect in collagen structure, recent evidence from murine studies indicates that $\mathrm{Scl}-\mathrm{Ab}$ treatments increase whole bone mechanical strength in the skeleton of OI mouse models [83], through an increase in overall bone mass and altered bone matrix chemistry (e.g., mineral to matrix ratio) [84]. This rescue appears to be effective with models of both dominant mild OI (Brtl/ + mice) $[83,85]$ and recessive OI ( $\mathrm{Crap}^{-/-}$mice) [86]. However, Scl-Ab treatment was unable to improve bone strength in a mouse model of dominant severe OI (Colla $1^{\mathrm{Jrt} / \mathrm{+}}$ mice) [87], suggesting that efficacy of this therapy may be limited to particular OI patient populations. 


\section{Fracture Healing}

Sclerostin-deficient mice demonstrate enhanced skeletal healing as compared to wild-type mice [88]. From a translational perspective, it is more interesting to ask whether systemic administration of a Scl-Ab would enhance fracture repair. Animal studies seem promising, as both stabilized bone defects [89-92] and closed fractures [93, 94] heal more rapidly with Scl-Ab administration. Despite success in these animal models, manufactures of romosozumab abandoned efforts to develop this treatment as a fracture-healing therapeutic agent; preliminary data from phase II studies suggest that treated patients do not demonstrate enhanced time to radiological healing [95]. Thus, sclerostin antibody therapy may be more effective at preventing the onset of new fractures as compared to promoting enhanced healing of existing fractures.

\section{Potential Issues with Anti-Sclerostin Therapies}

Despite widespread enthusiasm for developing Scl-Ab therapies as osteogenic agents, concerns have emerged regarding potential side effects. In a recent study, researchers identified that sclerostin is specifically expressed in synovial tissues of patients with rheumatoid arthritis (RA), and subsequent animal studies suggested that expression plays a protective role in the body. Specifically, when mice lacking sclerostin are crossed onto the background of a TNF-dependent RA model (human TNF- $\alpha$ transgenic mice), the double-mutant animals demonstrate enhanced joint inflammation and damage to the cartilage and bone $[14 \bullet \cdot$ ]. This suggests that $\mathrm{Scl}-\mathrm{Ab}$ treatments could be contraindicated in patients with TNF-dependent arthritis. However, these negative effects were not seen in nonTNF-dependent RA models, and it has also been recently shown that Scl-Ab treatment of human TNF transgenic mice prevents bone and cartilage erosion associated with RA without exacerbating inflammatory metrics like paw swelling and grip strength [96]. Conflicting conclusions between these studies have not yet been reconciled.

\section{Conclusion}

New anabolic skeletal therapies are needed to treat osteoporosis in the aging population. Pre-clinical and clinical studies demonstrate that targeting sclerostin with neutralizing antibodies releases an inhibitory brake on osteogenic Wnt signaling, promoting new bone formation and suppressing bone resorption to ultimately increase net bone mass. While recent studies have revealed a great deal of information regarding sclerostin's biological effects and regulatory patterns, much remains to be learned about the role of this molecule in the skeleton and other body systems.
Acknowledgments Funding to MWH is provided by the National Institute on Aging (NIA AG036675), and funding to MEML is provided by the American Diabetes Association (1-16-JDF-062).

\section{Compliance with Ethical Standards}

Conflict of Interest Meghan E. McGee-Lawrence and Mark W. Hamrick declare that they have no conflict of interest.

Human and Animal Rights and Informed Consent This article does not contain any studies with human or animal subjects performed by any of the authors.

\section{References}

Papers of particular interest, published recently, have been highlighted as:

- Of importance

•- Of major importance

1. Wright NC, Looker AC, Saag KG, Curtis JR, Delzell ES, Randall $\mathrm{S}$, et al. The recent prevalence of osteoporosis and low bone mass in the United States based on bone mineral density at the femoral neck or lumbar spine. J Bone Miner Res. 2014.

2. Cosman F, de Beur SJ, LeBoff MS, Lewiecki EM, Tanner B, Randall S, et al. Clinician's guide to prevention and treatment of osteoporosis. Osteoporos Int. 2014;25(10):2359-81.

3. AAOS. The burden of musculoskeletal diseases in the United States. Rosemond: American Academy of Orthopaedic Surgeons; 2008.

4. Stolzing A, Jones E, McGonagle D, Scutt A. Age-related changes in human bone marrow-derived mesenchymal stem cells: consequences for cell therapies. Mech Ageing Dev. 2008;129(3):163-73.

5. Pazianas M. Anabolic effects of PTH and the 'anabolic window'. Trends Endocrinol Metab. 2015;26(3):111-3.

6. Balemans W, Ebeling M, Patel N, Van Hul E, Olson P, Dioszegi M, et al. Increased bone density in sclerosteosis is due to the deficiency of a novel secreted protein (SOST). Hum Mol Genet. 2001;10(5): 537-43.

7. Balemans W, Patel N, Ebeling M, Van Hul E, Wuyts W, Lacza C, et al. Identification of a $52 \mathrm{~kb}$ deletion downstream of the SOST gene in patients with van Buchem disease. J Med Genet. 2002;39(2):917.

8. Brunkow ME, Gardner JC, Van Ness J, Paeper BW, Kovacevich $\mathrm{BR}$, Proll S, et al. Bone dysplasia sclerosteosis results from loss of the SOST gene product, a novel cystine knot-containing protein. Am J Hum Genet. 2001;68(3):577-89.

9. Fijalkowski I, Geets E, Steenackers E, Van Hoof V, Ramos FJ, Mortier G, et al. A novel domain-specific mutation in a sclerosteosis patient suggests a role of LRP4 as an anchor for sclerostin in human bone. J Bone Miner Res. 2016;31(4):874-81.

10. Li X, Zhang Y, Kang H, Liu W, Liu P, Zhang J, et al. Sclerostin binds to LRP5/6 and antagonizes canonical Wnt signaling. J Biol Chem. 2005;280(20):19883-7.

11. Ota K, Quint P, Ruan M, Pederson L, Westendorf JJ, Khosla S, et al. Sclerostin is expressed in osteoclasts from aged mice and reduces osteoclast-mediated stimulation of mineralization. J Cell Biochem. 2013;114(8):1901-7.

12. Brandenburg VM, Kramann R, Koos R, Kruger T, Schurgers L, Muhlenbruch $G$, et al. Relationship between sclerostin and 
cardiovascular calcification in hemodialysis patients: a crosssectional study. BMC Nephrol. 2013;14:219.

13. Zhu D, Mackenzie NC, Millan JL, Farquharson C, MacRae VE. The appearance and modulation of osteocyte marker expression during calcification of vascular smooth muscle cells. PLoS One. 2011;6(5):e19595.

14.• Wehmeyer C, Frank S, Beckmann D, Bottcher M, Cromme C, Konig U, et al. Sclerostin inhibition promotes TNF-dependent inflammatory joint destruction. Sci Transl Med. 2016;8(330): 330ra35. Sclerostin targeting antibodies are under investigation for preventing inflammatory bone loss. Surprisingly, in these studies, sclerostin inhibition instead exacerbated joint destruction in a rodent model of tumor necrosis factor $\alpha(\mathrm{TNF} \alpha)$-dependent rheumatoid arthritis. These results indicate that much remains to be learned about the role of sclerostin in the body, and suggest possible contraindications for sclerostin-targeting antibodies in certain patient populations.

15. van Bezooijen RL, Roelen BA, Visser A, van der Wee-Pals L, de Wilt E, Karperien M, et al. Sclerostin is an osteocyte-expressed negative regulator of bone formation, but not a classical BMP antagonist. J Exp Med. 2004;199(6):805-14.

16. Bellido T, Ali AA, Gubrij I, Plotkin LI, Fu Q, O’Brien CA, et al. Chronic elevation of parathyroid hormone in mice reduces expression of sclerostin by osteocytes: a novel mechanism for hormonal control of osteoblastogenesis. Endocrinology. 2005;146(11):4577-83.

17. Wijenayaka AR, Kogawa M, Lim HP, Bonewald LF, Findlay DM, Atkins GJ. Sclerostin stimulates osteocyte support of osteoclast activity by a RANKL-dependent pathway. PLoS One. 2011;6(10), e25900.

18. Ryan ZC, Ketha H, McNulty MS, McGee-Lawrence M, Craig TA, Grande JP, et al. Sclerostin alters serum vitamin D metabolite and fibroblast growth factor 23 concentrations and the urinary excretion of calcium. Proc Natl Acad Sci U S A. 2013;110(15):6199-204.

19. Li X, Ominsky MS, Niu QT, Sun N, Daugherty B, D'Agostin D, et al. Targeted deletion of the sclerostin gene in mice results in increased bone formation and bone strength. J Bone Miner Res. 2008;23(6):860-9.

20. Di Nisio A, De Toni L, Speltra E, Rocca MS, Taglialavoro G, Ferlin A, et al. Regulation of sclerostin production in human male osteocytes by androgens: experimental and clinical evidence. Endocrinology. 2015;156(12):4534-44.

21. Keller H, Kneissel M. SOST is a target gene for PTH in bone. Bone. 2005;37(2):148-58.

22. Gennari L, Merlotti D, Valenti R, Ceccarelli E, Ruvio M, Pietrini $\mathrm{MG}$, et al. Circulating sclerostin levels and bone turnover in type 1 and type 2 diabetes. J Clin Endocrinol Metab. 2012;97(5):1737-44.

23. Yu EW, Kumbhani R, Siwila-Sackman E, Leder BZ. Acute decline in serum sclerostin in response to PTH infusion in healthy men. $\mathrm{J}$ Clin Endocrinol Metab. 2011;96(11):E1848-51.

24. Rhee Y, Lee EY, Lezcano V, Ronda AC, Condon KW, Allen MR, et al. Resorption controls bone anabolism driven by parathyroid hormone $(\mathrm{PTH})$ receptor signaling in osteocytes. J Biol Chem. 2013;288(41):29809-20.

25. Li C, Wang W, Xie L, Luo X, Cao X, Wan M. Lipoprotein receptorrelated protein 6 is required for parathyroid hormone-induced Sost suppression. Ann N Y Acad Sci. 2016;1364(1):62-73.

26. Wein MN, Spatz J, Nishimori S, Doench J, Root D, Babij P, et al. HDAC5 controls MEF2C-driven sclerostin expression in osteocytes. J Bone Miner Res. 2015;30(3):400-11. These studies build upon earlier investigations and revealed important molecular mechanisms regulating sclerostin expression during osteocyte maturation.

27. Baertschi S, Baur N, Lueders-Lefevre V, Voshol J, Keller H. Class I and IIa histone deacetylases have opposite effects on sclerostin gene regulation. J Biol Chem. 2014;289(36):24995-5009.
28. Modder UI, Clowes JA, Hoey K, Peterson JM, McCready L, Oursler MJ, et al. Regulation of circulating sclerostin levels by sex steroids in women and in men. J Bone Miner Res. 2011;26(1):27-34.

29. Modder UI, Roforth MM, Hoey K, McCready LK, Peterson JM, Monroe DG, et al. Effects of estrogen on osteoprogenitor cells and cytokines/bone-regulatory factors in postmenopausal women. Bone. 2011;49(2):202-7.

30. Wijenayaka AR, Yang D, Prideaux M, Ito N, Kogawa M, Anderson $\mathrm{PH}$, et al. 1alpha,25-dihydroxyvitamin D3 stimulates human SOST gene expression and sclerostin secretion. Mol Cell Endocrinol. 2015;413:157-67.

31. Wijenayaka AR, Prideaux M, Yang D, Morris HA, Findlay DM, Anderson PH, et al. Early response of the human SOST gene to stimulation by 1alpha,25-dihydroxyvitamin D. J Steroid Biochem Mol Biol. 2015.

32. Sandal G, Pirgon O, Dundar B, Cetin H, Bayram HI. Serum sclerostin levels in newborns born to mothers with vitamin D deficiency. J Investig Med. 2015;63(7):878-81.

33. St John HC, Bishop KA, Meyer MB, Benkusky NA, Leng N, Kendziorski $\mathrm{C}$, et al. The osteoblast to osteocyte transition: epigenetic changes and response to the vitamin D3 hormone. Mol Endocrinol. 2014;28(7):1150-65.

34. Papanicolaou SE, Phipps RJ, Fyhrie DP, Genetos DC. Modulation of sclerostin expression by mechanical loading and bone morphogenetic proteins in osteogenic cells. Biorheology. 2009;46(5):389-99.

35. Robling AG, Niziolek PJ, Baldridge LA, Condon KW, Allen MR, Alam I, et al. Mechanical stimulation of bone in vivo reduces osteocyte expression of Sost/sclerostin. J Biol Chem. 2008;283(9): 5866-75.

36. Spatz JM, Wein MN, Gooi JH, Qu Y, Garr JL, Liu S, et al. The Wnt inhibitor sclerostin is up-regulated by mechanical unloading in osteocytes in vitro. J Biol Chem. 2015;290(27):16744-58. It was unclear whether disuse-induced increases in sclerostin expression occurred in a cell autonomous fashion or secondary to other changes such as reduced expression of parathyroid hormone. These studies revealed that sclerostin up-regulation in mechanical unloading occurs in a cell-autonomous fashion.

37. Frings-Meuthen P, Boehme G, Liphardt AM, Baecker N, Heer M, Rittweger J. Sclerostin and DKK1 levels during 14 and 21 days of bed rest in healthy young men. J Musculoskelet Neuronal Interact. 2013;13(1):45-52.

38. Delgado-Calle J, Riancho JA, Klein-Nulend J. Nitric oxide is involved in the down-regulation of SOST expression induced by mechanical loading. Calcif Tissue Int. 2014;94(4):414-22.

39. Spatz JM, Ellman R, Cloutier AM, Louis L, van Vliet M, Suva LJ, et al. Sclerostin antibody inhibits skeletal deterioration due to reduced mechanical loading. J Bone Miner Res. 2013;28(4):865-74.

40. Qin W, Li X, Peng Y, Harlow LM, Ren Y, Wu Y, et al. Sclerostin antibody preserves the morphology and structure of osteocytes and blocks the severe skeletal deterioration after motor-complete spinal cord injury in rats. J Bone Miner Res. 2015;30(11):1994-2004. Sclerostin-targeting antibodies prevented loss of lumbar vertebrae and hindlimb bone mass in a rat model of motor-complete spinal cord injury, suggesting potential for translation into a therapy useful for human spinal cord injury patients.

41. Tian X, Jee WS, Li X, Paszty C, Ke HZ. Sclerostin antibody increases bone mass by stimulating bone formation and inhibiting bone resorption in a hindlimb-immobilization rat model. Bone. 2011;48(2):197-201.

42. Zhang D, Hu M, Chu T, Lin L, Wang J, Li X, et al. Sclerostin antibody prevented progressive bone loss in combined ovariectomized and concurrent functional disuse. Bone. 2016.

43. Reppe S, Noer A, Grimholt RM, Halldorsson BV, Medina-Gomez C, Gautvik VT, et al. Methylation of bone SOST, its mRNA, and serum sclerostin levels correlate strongly with fracture risk in postmenopausal women. J Bone Miner Res. 2015;30(2):249-56. 
44. Leupin O, Kramer I, Collette NM, Loots GG, Natt F, Kneissel M, et al. Control of the SOST bone enhancer by PTH using MEF2 transcription factors. J Bone Miner Res. 2007;22(12):1957-67.

45. Nicodemus KK, Folsom AR. Iowa Women's Health S. Type 1 and type 2 diabetes and incident hip fractures in postmenopausal women. Diabetes Care. 2001;24(7):1192-7.

46. Giangregorio LM, Leslie WD, Lix LM, Johansson H, Oden A, McCloskey E, et al. FRAX underestimates fracture risk in patients with diabetes. J Bone Miner Res. 2012;27(2):301-8.

47. Neumann T, Hofbauer LC, Rauner M, Lodes S, Kastner B, Franke $\mathrm{S}$, et al. Clinical and endocrine correlates of circulating sclerostin levels in patients with type 1 diabetes mellitus. Clin Endocrinol (Oxf). 2014;80(5):649-55.

48. Starup-Linde J, Lykkeboe S, Gregersen S, Hauge EM, Langdahl BL, Handberg A, et al. Differences in biochemical bone markers by diabetes type and the impact of glucose. Bone. 2016;83:149-55.

49.• Daniele G, Winnier D, Mari A, Bruder J, Fourcaudot M, Pengou Z, et al. Sclerostin and insulin resistance in prediabetes: evidence of a cross talk between bone and glucose metabolism. Diabetes Care. 2015;38(8):1509-17. This paper demonstrates that sclerostin levels are correlated with insulin resistance in several metabolic tissues like the liver and skeletal muscle, and implicates the need for further studies to determine if and how this relationship factors into control of systemic glucose homeostasis by the skeleton.

50. Heilmeier U, Carpenter DR, Patsch JM, Harnish R, Joseph GB, Burghardt AJ, et al. Volumetric femoral BMD, bone geometry, and serum sclerostin levels differ between type 2 diabetic postmenopausal women with and without fragility fractures. Osteoporos Int. 2015;26(4):1283-93.

51. Yamamoto M, Yamauchi M, Sugimoto T. Elevated sclerostin levels are associated with vertebral fractures in patients with type 2 diabetes mellitus. J Clin Endocrinol Metab. 2013;98(10):4030-7.

52. Starup-Linde J, Lykkeboe S, Gregersen S, Hauge EM, Langdahl BL, Handberg A, et al. Bone structure and predictors of fracture in type 1 and type 2 diabetes. J Clin Endocrinol Metab. 2016;101(3): 928-36.

53. Joy MS, Karagiannis PC, Peyerl FW. Outcomes of secondary hyperparathyroidism in chronic kidney disease and the direct costs of treatment. J Manag Care Pharm. 2007;13(5):397-411.

54. Malluche HH, Davenport DL, Cantor T, Monier-Faugere MC. Bone mineral density and serum biochemical predictors of bone loss in patients with CKD on dialysis. Clin J Am Soc Nephrol. 2014;9(7):1254-62.

55. Pelletier S, Dubourg L, Carlier MC, Hadj-Aissa A, Fouque D. The relation between renal function and serum sclerostin in adult patients with CKD. Clin J Am Soc Nephrol. 2013;8(5):819-23.

56. Sabbagh Y, Graciolli FG, O'Brien S, Tang W, dos Reis LM, Ryan S, et al. Repression of osteocyte Wnt/beta-catenin signaling is an early event in the progression of renal osteodystrophy. J Bone Miner Res. 2012;27(8):1757-72.

57. Cejka D, Herberth J, Branscum AJ, Fardo DW, Monier-Faugere MC, Diarra D, et al. Sclerostin and Dickkopf-1 in renal osteodystrophy. Clin J Am Soc Nephrol. 2011;6(4):877-82.

58. Bonani M, Rodriguez D, Fehr T, Mohebbi N, Brockmann J, Blum $\mathrm{M}$, et al. Sclerostin blood levels before and after kidney transplantation. Kidney Blood Press Res. 2014;39(4):230-9.

59. Rhee Y, Kim WJ, Han KJ, Lim SK, Kim SH. Effect of liver dysfunction on circulating sclerostin. J Bone Miner Metab. 2014;32(5): 545-9.

60. Gonzalez-Reimers E, Martin-Gonzalez C, de la Vega-Prieto MJ, Pelazas-Gonzalez R, Fernandez-Rodriguez C, Lopez-Prieto J, et al. Serum sclerostin in alcoholics: a pilot study. Alcohol Alcohol. 2013;48(3):278-82.

61. Guanabens N, Ruiz-Gaspa S, Gifre L, Miquel R, Peris P, Monegal A, et al. Sclerostin expression in bile ducts of patients with chronic cholestasis may influence the bone disease in primary biliary cirrhosis. J Bone Miner Res. 2016.

62. Yong MK, Elliott JH, Woolley IJ, Hoy JF. Low CD4 count is associated with an increased risk of fragility fracture in HIV-infected patients. J Acquir Immune Defic Syndr. 2011;57(3):205-10.

63. Almansouri AY, Abdulfatah ME, Baaqil OH, Bakheet AA, Turki SA, Kotb MM, et al. Serum sclerostin levels in patients with human immunodeficiency virus infection and their association with bone turnover markers and bone mineral densitometry. J Bone Metab. 2016;23(1):16-22.

64. Mora S, Puzzovio M, Giacomet V, Fabiano V, Maruca K, Capelli S, et al. Sclerostin and DKK-1: two important regulators of bone metabolism in HIV-infected youths. Endocrine. 2015;49(3):783-90.

65. Li X, Ominsky MS, Warmington KS, Morony S, Gong J, Cao J, et al. Sclerostin antibody treatment increases bone formation, bone mass, and bone strength in a rat model of postmenopausal osteoporosis. J Bone Miner Res. 2009;24(4):578-88.

66. Ominsky MS, Niu QT, Li C, Li X, Ke HZ. Tissue-level mechanisms responsible for the increase in bone formation and bone volume by sclerostin antibody. J Bone Miner Res. 2014;29(6):1424-30.

67. Stolina M, Dwyer D, Niu QT, Villasenor KS, Kurimoto P, Grisanti $\mathrm{M}$, et al. Temporal changes in systemic and local expression of bone turnover markers during six months of sclerostin antibody administration to ovariectomized rats. Bone. 2014;67:305-13.

68. Li X, Warmington KS, Niu QT, Asuncion FJ, Barrero M, Grisanti $\mathrm{M}$, et al. Inhibition of sclerostin by monoclonal antibody increases bone formation, bone mass, and bone strength in aged male rats. $\mathrm{J}$ Bone Miner Res. 2010;25(12):2647-56.

69. Li X, Niu QT, Warmington KS, Asuncion FJ, Dwyer D, Grisanti M, et al. Progressive increases in bone mass and bone strength in an ovariectomized rat model of osteoporosis after 26 weeks of treatment with a sclerostin antibody. Endocrinology. 2014;155(12): 4785-97.

70. Taylor S, Ominsky MS, Hu R, Pacheco E, He YD, Brown DL, et al. Time-dependent cellular and transcriptional changes in the osteoblast lineage associated with sclerostin antibody treatment in ovariectomized rats. Bone. 2016;84:148-59.

71. Nioi P, Taylor S, Hu R, Pacheco E, He YD, Hamadeh H, et al. Transcriptional profiling of laser capture microdissected subpopulations of the osteoblast lineage provides insight into the early response to sclerostin antibody in rats. J Bone Miner Res. 2015;30(8): 1457-67.

72.• McClung MR, Grauer A, Boonen S, Bolognese MA, Brown JP, Diez-Perez A, et al. Romosozumab in postmenopausal women with low bone mineral density. N Engl J Med. 2014;370(5):412-20. Results in this manuscript document the successful outcome of the first Phase II studies with romosozumab, a sclerostintargeting antibody, in the treatment of post-menopausal osteoporosis.

73. Langdahl B, Libanati C, Crittenden D, Bolognese MA, Brown JP, Diaizadeh NS, et al. Superior gains in bone mineral density and estimated strength at the hip for romosozumab compared with teriparatide in women with postmenopausal osteoporosis transitioning from bisphosphonate therapy: results of the phase 3 open-label structure study, ENDO 2016. Boston: Endocrine Society; 2016.

74. Recker RR, Benson CT, Matsumoto T, Bolognese MA, Robins DA, Alam J, et al. A randomized, double-blind phase 2 clinical trial of blosozumab, a sclerostin antibody, in postmenopausal women with low bone mineral density. J Bone Miner Res. 2015;30(2):216-24. This report documents the success of blosozumab, a romosozumab competitor, in Phase II studies of post-menopausal women.

75. Recknor CP, Recker RR, Benson CT, Robins DA, Chiang AY, Alam $J$, et al. The effect of discontinuing treatment with blosozumab: follow-up results of a phase 2 randomized clinical trial in postmenopausal women with low bone mineral density. J Bone 
Miner Res. 2015;30(9):1717-25. Patients treated with blosozumab maintain higher bone mass at the lumbar spine and hip as compared to placebo treated subjects at least one year after discontinuing treatment, suggesting long-term efficacy of sclerostin-targeting therapies.

76. Padhi D, Allison M, Kivitz AJ, Gutierrez MJ, Stouch B, Wang C, et al. Multiple doses of sclerostin antibody romosozumab in healthy men and postmenopausal women with low bone mass: a randomized, double-blind, placebo-controlled study. J Clin Pharmacol. 2014;54(2):168-78. Along with the publication from Graeff et al., this small phase 1b study demonstrates the efficacy of romosozumab in improving low bone mass (measured by DXA) in male as well as female subjects.

77.• Graeff C, Campbell GM, Pena J, Borggrefe J, Padhi D, Kaufman A, et al. Administration of romosozumab improves vertebral trabecular and cortical bone as assessed with quantitative computed tomography and finite element analysis. Bone. 2015;81:364-9. Along with the publication from Padhi et al., this phase $1 \mathrm{~b}$ study, although small, utilized high-resolution QCT to demonstrate the efficacy of romosozumab in improving low bone mass in male as well as female subjects.

78. Roforth MM, Fujita K, McGregor UI, Kirmani S, McCready LK, Peterson JM, et al. Effects of age on bone mRNA levels of sclerostin and other genes relevant to bone metabolism in humans. Bone. 2014;59:1-6.

79. Yao W, Dai W, Jiang L, Lay EY, Zhong Z, Ritchie RO, et al. Sclerostin-antibody treatment of glucocorticoid-induced osteoporosis maintained bone mass and strength. Osteoporos Int. 2016;27(1): 283-94.

80. Beggs LA, Ye F, Ghosh P, Beck DT, Conover CF, Balaez A, et al. Sclerostin inhibition prevents spinal cord injury-induced cancellous bone loss. J Bone Miner Res. 2015;30(4):681-9.

81. Ward LM, Rauch F, Whyte MP, D'Astous J, Gates PE, Grogan D, et al. Alendronate for the treatment of pediatric osteogenesis imperfecta: a randomized placebo-controlled study. J Clin Endocrinol Metab. 2011;96(2):355-64.

82. Rauch F, Munns CF, Land C, Cheung M, Glorieux FH. Risedronate in the treatment of mild pediatric osteogenesis imperfecta: a randomized placebo-controlled study. J Bone Miner Res. 2009;24(7): $1282-9$.

83. Sinder BP, Salemi JD, Ominsky MS, Caird MS, Marini JC, Kozloff KM. Rapidly growing Brtl/+ mouse model of osteogenesis imperfecta improves bone mass and strength with sclerostin antibody treatment. Bone. 2015;71:115-23.

84. Sinder BP, Lloyd WR, Salemi JD, Marini JC, Caird MS, Morris $\mathrm{MD}$, et al. Effect of anti-sclerostin therapy and osteogenesis imperfecta on tissue-level properties in growing and adult mice while controlling for tissue age. Bone. 2016;84:222-9.

85. Sinder BP, White LE, Salemi JD, Ominsky MS, Caird MS, Marini JC, et al. Adult Brtl/+ mouse model of osteogenesis imperfecta demonstrates anabolic response to sclerostin antibody treatment with increased bone mass and strength. Osteoporos Int. 2014;25(8): 2097-107.

86. Grafe I, Alexander S, Yang T, Lietman C, Homan EP, Munivez E, et al. Sclerostin antibody treatment improves the bone phenotype of Crtap mice, a model of recessive osteogenesis imperfecta. J Bone Miner Res. 2015.

87. Roschger A, Roschger P, Keplingter P, Klaushofer K, Abdullah S, Kneissel M, et al. Effect of sclerostin antibody treatment in a mouse model of severe osteogenesis imperfecta. Bone. 2014;66:182-8.

88. McGee-Lawrence ME, Ryan ZC, Carpio LR, Kakar S, Westendorf JJ, Kumar R. Sclerostin deficient mice rapidly heal bone defects by activating beta-catenin and increasing intramembranous ossification. Biochem Biophys Res Commun. 2013;441(4):886-90.

89. Alzahrani MM, Rauch F, Hamdy RC. Does sclerostin depletion stimulate fracture healing in a mouse model? Clin Orthop Relat Res. 2016;474(5):1294-302.

90. Feng G, Chang-Qing Z, Yi-Min C, Xiao-Lin L. Systemic administration of sclerostin monoclonal antibody accelerates fracture healing in the femoral osteotomy model of young rats. Int Immunopharmacol. 2015;24(1):7-13.

91. Alaee F, Virk MS, Tang H, Sugiyama O, Adams DJ, Stolina M, et al. Evaluation of the effects of systemic treatment with a sclerostin neutralizing antibody on bone repair in a rat femoral defect model. J Orthop Res. 2014;32(2):197-203.

92. Jawad MU, Fritton KE, Ma T, Ren PG, Goodman SB, Ke HZ, et al. Effects of sclerostin antibody on healing of a non-critical size femoral bone defect. J Orthop Res. 2013;31(1):155-63.

93. Liu Y, Rui Y, Cheng TY, Huang S, Xu L, Meng F, et al. Effects of sclerostin antibody on the healing of femoral fractures in ovariectomised rats. Calcif Tissue Int. 2016;98(3):263-74.

94. Morse A, Yu NY, Peacock L, Mikulec K, Kramer I, Kneissel M, et al. Endochondral fracture healing with external fixation in the Sost knockout mouse results in earlier fibrocartilage callus removal and increased bone volume fraction and strength. Bone. 2015;71:15563.

95. Larsson S. Anti-sclerostin — is there an indication? Injury. 2016;47 Suppl 1:S31-5.

96. Chen XX, Baum W, Dwyer D, Stock M, Schwabe K, Ke HZ, et al. Sclerostin inhibition reverses systemic, periarticular and local bone loss in arthritis. Ann Rheum Dis. 2013;72(10):1732-6. 